\title{
Comparative analysis of photovoltaic modules center and edge temperature using IoT embedded system
}

\author{
Renata I. S. Pereira ${ }^{1}$, Sandro C. S. Jucá ${ }^{2}$, Paulo C. M. Carvalho ${ }^{1}$ and Luis M. Fernández-Ramírez ${ }^{3}$ \\ ${ }^{1}$ Department of Electrical Engineering \\ Federal University of Ceará (UFC) \\ Pici Campus, Mister Hull Av., s/n - Fortaleza, 60455-760, Ceará (Brazil) \\ Phone: +558533669585, Fax:+558533669574, e-mail: renata@dee.ufc.br, carvalho@dee.ufc.br \\ ${ }^{2}$ Academic Master's Program in Renewable Energy (PPGER) \\ Federal Institute of Ceará (IFCE) \\ Maracanaú Campus, Parque Central Av., s/n - Industrial District I, 61939-140, Ceará (Brazil) \\ Phone: +558538786333, Fax: +558538786300, e-mail: sandrojuca@ifce.edu.br \\ ${ }^{3}$ Research Group in Electrical Technologies for Sustainable and Renewable Energy (PAIDI-TEP-023) \\ Department of Electrical Engineering, University of Cadiz (UCA) \\ Escuela Politécnica Superior de Algeciras, Av. Ramón Puyol, s/n, 11202 Algeciras (Spain) \\ Phone: +34956028166, e-mail: luis.fernandez@uca.es
}

\begin{abstract}
The main objective of this project is to develop and implement an Internet of Things (IoT) monitoring system to analyze the temperature at the center and at the edge of gridconnected photovoltaic (PV) modules at Maracanaú - CE, Brazil. The proposed IoT embedded system is based on free software and hardware using ESP 32 development board, allowing online distribution, free usage and communication with a server in the Cloud wirelessly via WiFi. The use of open source and cross-platform (Linux, Windows ${ }^{\circledR}$ and Mac OSX) allows greater interaction and accessibility to the user. A web page called Web Monitor was developed for online data consulting and for real-time monitoring of the PV temperature. Monitoring individual PV modules has the objective of providing data for the analysis of electricity generation efficiency and for fault detection in case of PV cells overheating. Meteorological data such as solar irradiance, ambient temperature, relative humidity and wind speed were also measured and monitored to allow a more complete analysis of the effect of these variables on the module temperature response. According to the results, the PV module edge temperature is 1.5 to $2^{\circ} \mathrm{C}$ lower than the center temperature.
\end{abstract}

\section{Key words}

Photovoltaic generation, temperature monitoring, IoT.

\section{Introduction}

Data acquisition and monitoring systems are important in the evaluation of the solar potential of a region, in the prognosis of failures, in the practical verification of project data, as well as in the optimization of conversion efficiency [1]. With the growth of PV decentralized power generation units, the modularization of these monitoring systems is only possible with the reduction of costs and flexibility of installation and maintenance. With the aim of modularizing, reducing costs and making the online monitoring system even more practical and fast in data processing, a free software and hardware monitoring system is proposed using the Internet of Things (IoT) concept. Therefore, due to the low cost (around US\$8), the IoT ESP 32 module [2] was selected, configured and implemented to collect irradiance and temperature data from the PV modules. The previous version, IoT ESP 8266 [3] (around US\$3) was also implemented for monitoring wind speed, ambient temperature and relative humidity. The IoT monitoring was installed and tested in three PV plants: Fortaleza and Maracanaú, both in the Brazilian state of Ceará, and Cologne - Germany. In this paper, the analysis of temperature at the center and at the edge of PV modules located at Maracanaú - CE (Lat.: 3.872287, Long.: -38.612233 ) is developed.

Only 13 to $18 \%$ of the solar energy is converted into electricity (PV efficiency). Losses in the form of heat in the solar cell cause an increase in the temperature of the PV module, which reduces the electrical efficiency, increasing the saturation current of this module. Therefore, each degree above the Nominal Operating Cell Temperature (NOCT) corresponds to $0.45 \%$ decrease in cell efficiency [4] for the polycrystalline silicon module used [5]. NOCT corresponds to $45^{\circ} \mathrm{C}\left( \pm 2^{\circ} \mathrm{C}\right)$ for the module, however it is necessary to observe the datasheet of the module as it varies according to the PV technology used by the manufacturer. The IoT system for PV temperature monitoring is designed for data collection and practical verification of values previously estimated with mathematical models. Due to the limited availability of measured data around the world, a validated model for 
temperature estimation of the PV module is required [6], while a global IoT monitoring network is not available. Several articles carried out mathematical modelling to estimate the efficiency of the PV cell according to the effect of temperature using variables such as wind speed, solar irradiance and ambient temperature [7]. The Faiman model was compared and validated in [8] with other models for five different regions of the world. The authors use the average between center and edge PV module temperature to implement mathematical models of PV temperature estimation in external conditions in five different countries.

There is a vast literature available on research on temperature modelling of the PV silicon module from measured data and estimative calculations. However, after applying the models of Duffie and Beckman [9], Ross [10] and Chenni [11] with data measured at the Alternative Energy Laboratory at the Federal University of Ceará (LEA-UFC), it was verified that none fit the conditions of the equatorial region of Fortaleza, Brazil (Lat.: -3.737491, Long.: -38.572781) [12], city located 20 $\mathrm{km}$ from Maracanaú. Hence, temperature monitoring to obtain measured data is necessary.

In Brazilian plants, the high temperatures at which the PV modules work have been neglected. In Europe, for example, where the ambient temperature is lower, and the seasons are well defined, the temperature of the PV module does not become as worrying for electrical efficiency as it is in Brazil, mainly in the Northeast region, near the Equator, where 12 Sun hours per day are recorded and average daily irradiation is $5.5 \mathrm{kWh} / \mathrm{m}^{2}$. In the rainy season (from January to June in this region), there is a reduction of the irradiation, which reduces the PV module temperature, but also reduces the electricity generation.

\section{Literature Review}

IoT, the communication between devices without human intervention [13], understands each device as a small part of the Internet. Such small devices can, in a practical way, interact and communicate, maximizing modularity, comfort, convenience, safety and energy savings. Wireless technologies such as WiFi/3GPP, Bluetooth and Radio are preferred for decentralized systems [14], [15] but Ethernet cable is also an alternative for centralized systems.

IoT is the solution for the reduction of energy consumption in this new era that demands the insertion of technology and communication via the internet in several sectors such as industrial, commercial and residential [16]. The term Internet of Energy (IoE) is the intelligent monitoring and control of energy consumption. From the moment one has the user's consumption profile, through sensor data, it is possible to identify and optimize the use of energy, making the process more efficient and economical. Hence, both renewable energy and IoT systems are the basis for sustainability in terms of electricity consumption. According to the author, two billion people currently have access to the Internet, and it is estimated that in a decade a good part of the services will be interconnected and available online.
To implement an IoT system, a database is usually used to store the collected data. Cloud computing provides access to a shared set of configurable computing resources without requiring deep knowledge of management technologies [17]. The database Cloud model simplifies the installation, operation and maintenance of information systems, increasing the effectiveness and reliability of the system, reducing costs.

An Arduino-based data acquisition and transmission system (DATS) with local control and SD card storage, supporting 16 sensors, for PV systems temperature measurement is proposed by [18]. A low-cost, computerbased open source DATS for general data acquisition is also proposed in [19] using a dedicated PC with USB or Serial RS-232 interface for communication, which requires installation of a driver to generate a virtual COM port. The system is compatible with LabVIEW ${ }^{\text {TM }}$ (Laboratory Virtual Instrument Engineering Workbench) [20] and the used analog-to-digital (AD) converter has a 16-bit resolution.

The system proposed by [21] monitors meteorological and inverter data in a grid-connected PV plant. The hardware is based on PcDuino (discontinued) and stores data on a SD card as well as sends over the Internet. PcDuino combines Arduino with $\mathrm{RPi}$, operates on Linux and features HDMI interface, USB, input/output pins, SD card slot, $512 \mathrm{MB}$ of DRAM memory, $1 \mathrm{GHz}$ processor, six channels AD, UART, SPI, I ${ }^{2} \mathrm{C}$. Data from 20 PV plants are monitored from 2016 to 2017. Additionally, the authors present a bibliographic review comparing 23 projects. Surveyed projects implement low-cost hardware solutions with PIC microcontrollers and Arduino, but also commercial dataloggers. Data are usually locally stored via serial interface (RS232) or dedicated PC and those who have implemented wireless communication have used ZigBee or Radio Frequency. Authors claim that commercial dataloggers have disadvantages such as high cost, low memory, connection to a PC, low programming flexibility requiring proprietary interface software and offer few sensor inputs. Data is then sent to the Internet via RJ45 wired connection to the Internet modem.

The design of [22] describes a network of wireless sensors and proposes to use Arduino or Raspberry to interface sensors. From the moment intelligent sensor nodes receive antennas for wireless communication and an IP of the Internet network, they can synchronize different devices and share data between them or with a central hub, which guarantees new possibilities of efficient communication in sensors networks. With the goal of reducing the power consumption of these nodes, which may have sending rates every minute, for example, sources such as solar PV have been applied to recharge the system batteries.

Hence, we propose an IoT monitoring network WiFi connected to the Cloud to provide important data on PV analysis and fault identification worldwide accessible. We present also a complete monitoring system: monitoring of all the required variables, data transmission to the Cloud and Web Monitor for remote and real-time data visualization [23]. The proposed system provides 
meteorological data and PV module temperature; both analyzed together with electric generation data from the PV inverters. We apply only the ESP 32 board (US\$ 8) for data sensing, processing and transmission. Considering the literature review, the systems fail in meeting all these points together.

\section{PV IoT monitoring system}

It is observed the need for monitoring individual PV modules for a more accurate analysis and for ease of the fault detection, being able to identify which specific module presents problems. The operation of the IoT monitoring system presents the following steps:

1) Data acquisition with IoT system;

2) Sending the measured data to the Cloud server via $\mathrm{WiFi}$;

3) Data is displayed to users on the online Web Monitor.

The sensor data are sent every minute, 24 hours/day, to the Cloud MySQL database. The IEC 61724:1998 standard specifies that the sampling interval for parameters that vary directly with the irradiance should be 1 minute or less. For parameters that have larger time constants, such as temperature, an arbitrary interval can be specified between 1 and 10 minutes [24]. The developed Web Monitor in PHP is effective due to the online consulting of the data and the real-time monitoring of the PV plant. The use of open source and cross-platform software (Linux, Windows ${ }^{\circledR}$ and Mac OSX) for online microgeneration monitoring systems allows greater user interaction and accessibility due to the possibility of free distribution [25], [26].

The Maracanaú plant monitors the PV temperature data at the center and the edge of the module and solar irradiance using ESP 32. ESP 8266 is responsible for ambient temperature, relative humidity and wind speed data. The modules of the Maracanaú PV plant $(1.35 \mathrm{kWp})$ are geographically oriented South with $10^{\circ}$ slope. PT100 temperature sensors were used to measure the temperature at the edge and at the center of the PV modules. From the bibliographical research presented, studies verified difference of 1 to $2^{\circ} \mathrm{C}$ between the center and the edge of the module.

Figure 1 shows the IoT monitoring system components implemented at the Maracanaú PV plant. A second class LP02 Hukseflux pyranometer was implemented for reading irradiance in the inclined plane and for temperature monitoring of five PV modules, eight PT100 sensors (five at the center (PV 1a, 2a, 3a, 4a and 5a) and three at the edges: left (PV1b), center (PV3b) and right (PV5b) of the string.

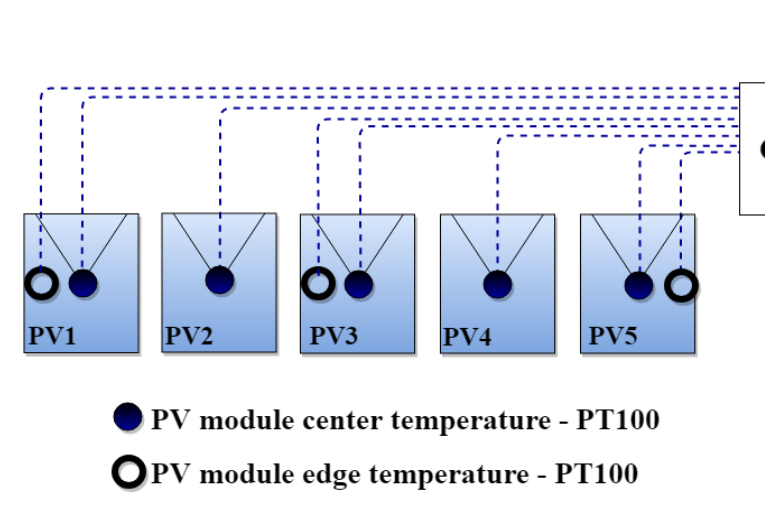

Fig. 1. Maracanaú IoT monitoring system and sensors.

According to Figure 2, the five modules are positioned in line and with $2 \mathrm{~cm}$ of distance between modules (distance from the intermediate fixing clamp). Between the PV modules 4 and 5, the anemometer NRG \#40C was installed with the same slope of the PV modules, approximately $10^{\circ}$ South. The circuits for PT100, pyranometer and anemometer signal conditioning were calibrated from commercial equipment and presented measurements within the specific error range of each sensor. ESP 32 analog/digital converter was calibrated with a precision benchtop source to avoid measurement errors, considering the nonlinearity of the bit-voltage curve.

Due to the Maracanaú geographical position, $3.78^{\circ}$ below the Equator line, the PV modules orientation to the North or South by up to 15 degrees does not harm the generation of electricity. Figure 3 shows the PHB PV grid-tie inverter [27], string box and ESP 32 enclosure.

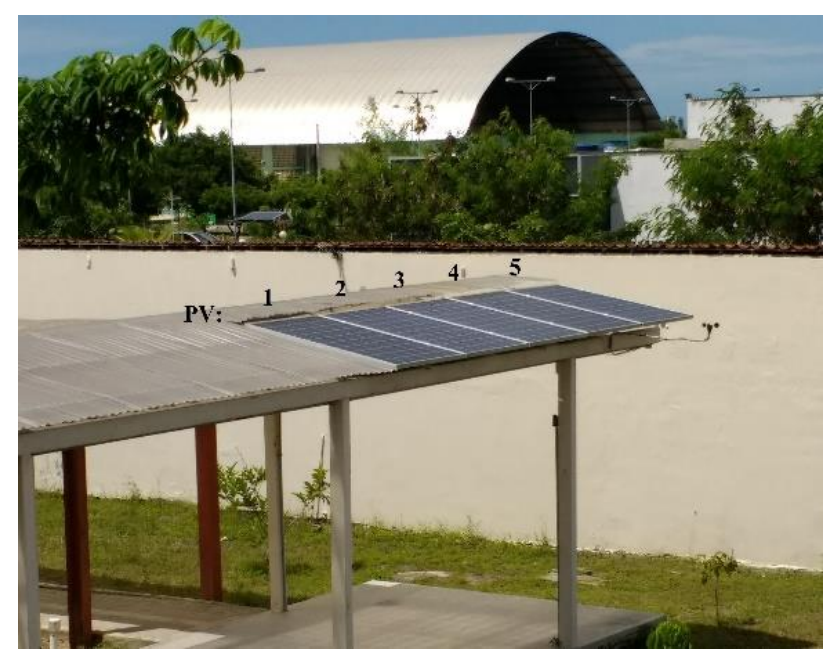

Fig. 2. Maracanaú PV plant. 


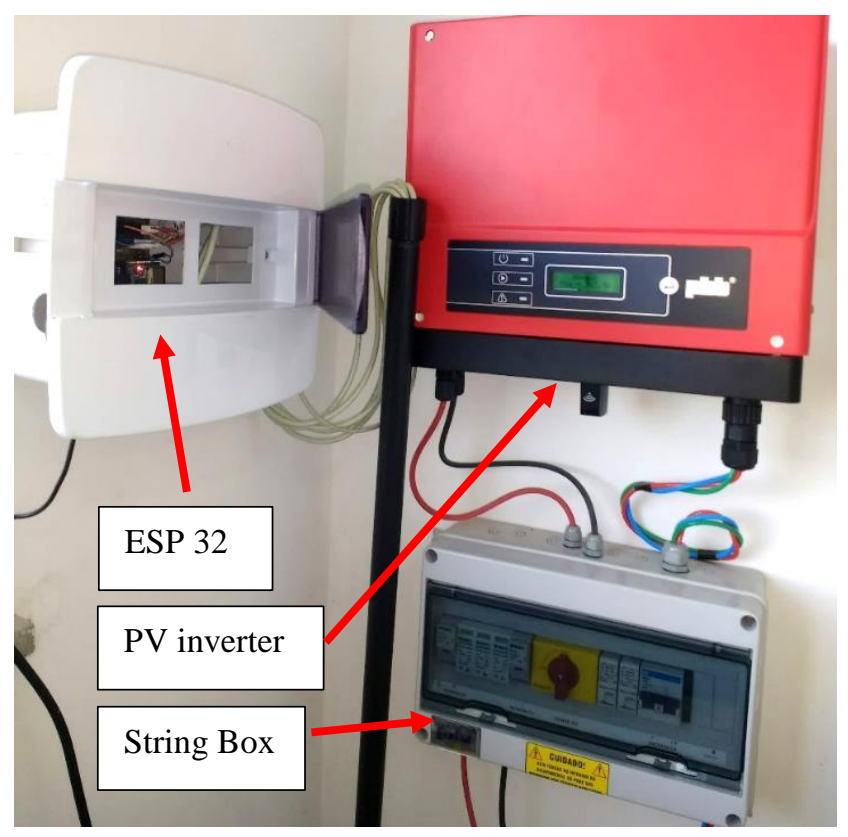

Fig. 3. PV inverter, string box and IoT system enclosure.

Three important parameters to analyze the PV generation are: yield, capacity factor $(\mathrm{CF})$ and performance ratio (PR).

Yield is the relation between the generated electricity $(\mathrm{kWh})$ and installed capacity $(\mathrm{kWp})$ of the PV plant, as in (1). Thus, it is possible to compare the productivity of one plant with another of different installed power capacity.

$$
Y \text { ield }=\frac{\text { Electricity generated }}{\text { Installed capacity }}\left(\frac{k W h}{k W p}\right)
$$

$\mathrm{CF}$ is the percentage index that represents the ratio of electricity generated over a period to the nominal generation capacity over the same period. This index allows to compare the electricity generation of different sources. CF is determined as in (2).

$$
C F=\frac{\text { Electricity generated }}{\text { Installed capacity } * 24 * n^{\circ} \text { days }}(\%)
$$

Performance Ratio (PR) is the ratio between the productivity and available irradiance, that is, between Yield and the amount of Sun hours at $1,000 \mathrm{~W} / \mathrm{m}^{2}$ in the analyzed perio, as in (3). PR considers all the efficiency losses including the module temperature increase, irradiance variation, dirt, connections and inverter losses. PV plants (modules, inverters, cables, accessories) can reach average PR of $80 \%$ up to $90 \%$ during the year [28], being possible to analyze the overall efficiency of the PV system. It is possible to act on a specific loss factor, such as dirt, cleaning the modules in a suitable period, increasing system performance and efficiency [29].

$$
P R=\frac{\text { Yield }}{\text { Irradiation }}(\%)
$$

PR is usually estimated in a project with the climatological data from the region of installation and insertion of losses. However, since the proposed monitoring has irradiance data measured by the pyranometer as from March 2018, the irradiation was calculated from the sum of the hourly means of irradiance on each day and then summed to generate the available monthly irradiance.

\section{Results}

Using the measured data, PV generation parameters (Yield, CF, PR, monthly and daily irradiation) are given in Table I.

Table I - PV generation parameters from March 2018 to March 2019

\begin{tabular}{|l|c|c|c|c|c|}
\hline Month & $\begin{array}{c}\text { Yield } \\
(\mathbf{k W h} / \mathbf{k W} \\
\mathbf{p})\end{array}$ & $\begin{array}{c}\mathbf{C F} \\
\mathbf{( \% )}\end{array}$ & $\begin{array}{c}\mathbf{P R} \\
(\mathbf{\%})\end{array}$ & $\begin{array}{c}\text { Monthly } \\
\text { irradiation } \\
\left(\mathbf{k W h} / \mathbf{m}^{2}\right)\end{array}$ & $\begin{array}{c}\text { Daily } \\
\text { irradiation } \\
\left(\mathbf{k W h} / \mathbf{m}^{2}\right)\end{array}$ \\
\hline Mar/18 & 130.2 & 18 & 92 & 142.0 & 4.1 \\
\hline Apr/18 & 118.0 & 16 & 91 & 130.1 & 4.4 \\
\hline May/18 & 102.4 & $\mathbf{1 4}$ & 78 & 143.7 & 4.6 \\
\hline June/18 & 113.3 & 16 & 77 & 147.4 & 4.9 \\
\hline July/18 & 119.6 & 16 & 76 & 156.7 & 5.1 \\
\hline Aug/18 & 135.9 & 18 & 78 & 173.3 & 5.6 \\
\hline Sep/18 & 142.7 & $\mathbf{2 0}$ & 78 & 181.8 & 6.0 \\
\hline Oct/18 & $\mathbf{1 4 9 . 2}$ & $\mathbf{2 0}$ & 79 & $\mathbf{1 8 9 . 3}$ & $\mathbf{6 . 1}$ \\
\hline Nov/18 & 143.8 & $\mathbf{2 0}$ & 80 & 179.2 & 5.9 \\
\hline Dec/18 & 138.9 & 19 & 94 & 148.3 & 4.8 \\
\hline Jan/19 & 134.7 & 18 & 124 & 108.9 & 3.5 \\
\hline Feb/19 & 98.8 & 15 & 123 & 80.6 & 2.9 \\
\hline Mar/19 & $\mathbf{8 7 . 9}$ & $\mathbf{1 2}$ & 117 & 75.0 & $\mathbf{2 . 5}$ \\
\hline
\end{tabular}

The lowest CFs of the analyzed period were $14 \%$ registered in May/18 and $12 \%$ in Mar/19. The highest (20\%) ones were registered in Sep, Oct and Nov/18. Mar/19 was the month with the lowest average daily irradiance of $2.5 \mathrm{kWh} / \mathrm{m}^{2}$ and Oct/18 the highest, 6.1 $\mathrm{kWh} / \mathrm{m}^{2}$, with monthly irradiance $189.3 \mathrm{kWh} / \mathrm{m}^{2}$.

The average yearly performance ratio for the analyzed period was $91 \%$. The highest productivity was Oct/18, totaling $149.2 \mathrm{kWh} / \mathrm{kWp}$ and the lowest was 87.9 $\mathrm{kWh} / \mathrm{kWp}$ registered in Mar/19.

Figure 4 shows productivity and CF; Figure 5 shows monthly irradiation and PR. According to the data, the second semester has better productivity and consequently better CF. 


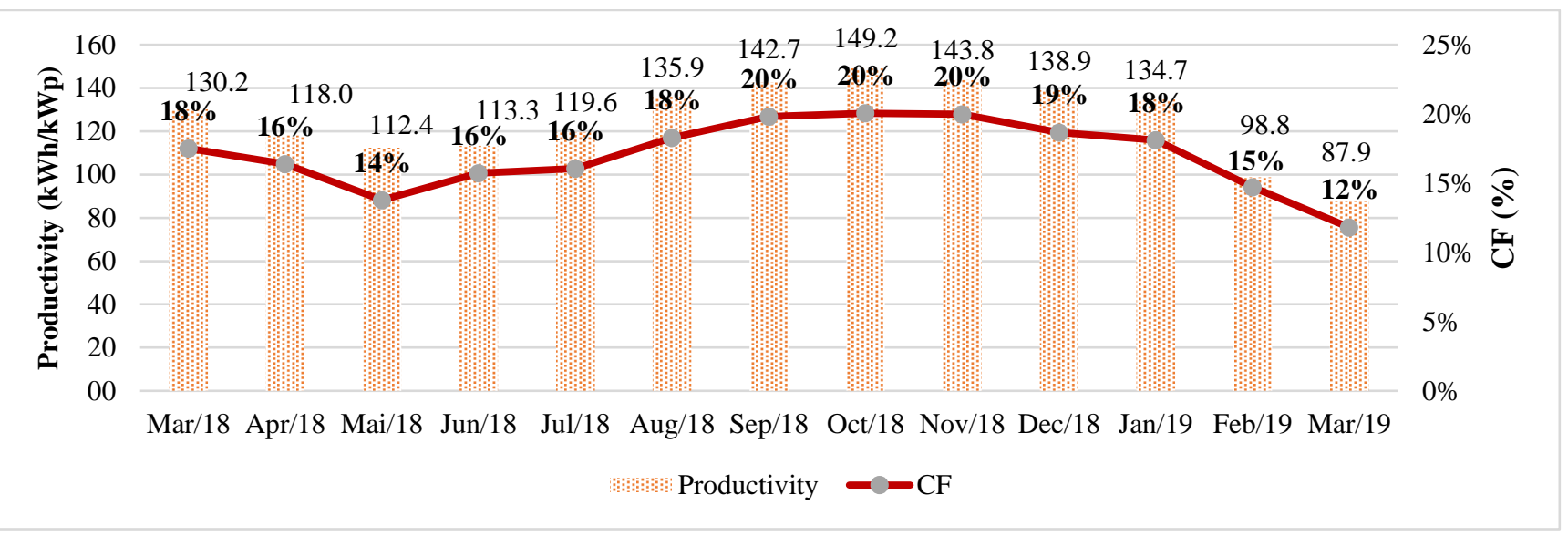

Fig. 4. Productivity and CF from March 2018 to March 2019.

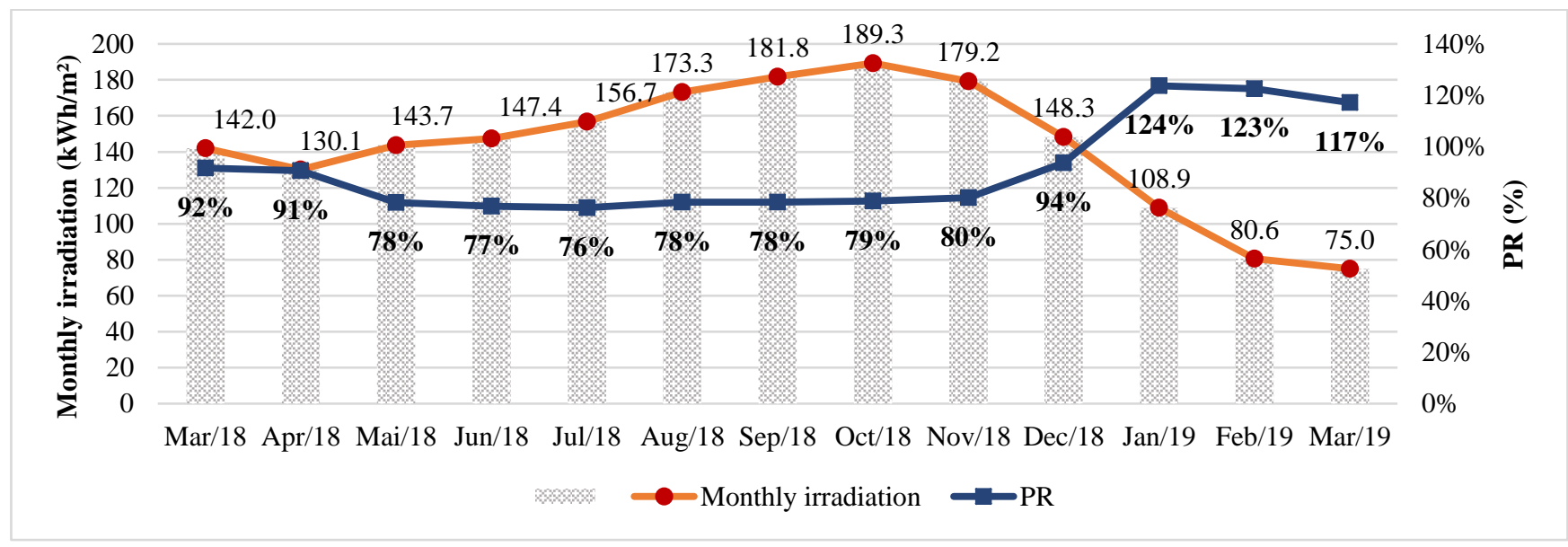

Fig. 5. Monthly irradiation and PR from March 2018 to March 2019.

As irradiation increases, meaning more productivity, PR decreases. This is because the system efficiency decreases with high PV module temperatures. PR is greater from Jan/19 to Mar/19, when irradiation is lower. Although the first semester is the rainy period in the Brazilian Northeast, the low irradiation levels (108.9, 80.6 and 75.0 $\mathrm{kWh} / \mathrm{m}^{2}$ ) are below the average levels, due to the high precipitations in the current year.
Although the period from Mar/18 to Sep/18 shows some rainy periods, mainly in the first semester, the PV modules average temperature still reaches high values, according to Figure 6. The maximum temperature reaches $47.3^{\circ} \mathrm{C}$ at noon. In relation to the Sun hours, Maracanaú has an average of 12 hours of Sun daily throughout the year. In the first semester, the Sun rises around 5:40 am and sets at $5: 50 \mathrm{pm}$; and in the second half, it rises normally at 5:10 am and sets at 5:25 pm.

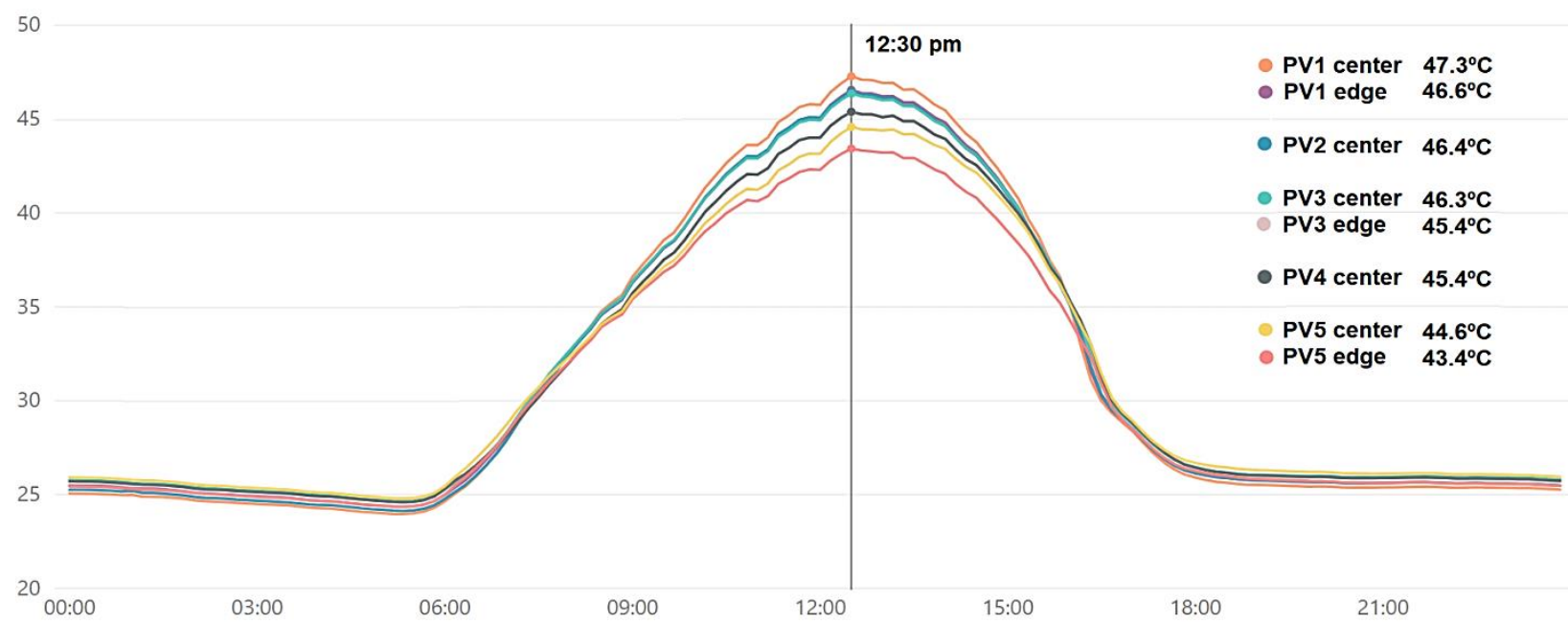

Fig. 6. Average PV module temperature $\left({ }^{\circ} \mathrm{C}\right)$ from March to September 2018. 
Figure 7 shows the monthly average PV module temperatures in October 2018, month with the highest electricity generation for the analyzed period. The productivity was $149.2 \mathrm{kWh} / \mathrm{kWp}$ from $189.3 \mathrm{kWh} / \mathrm{m}^{2}$, totaling $79 \% \mathrm{PR}$ and $20 \% \mathrm{CF}$. A peak of $50.4^{\circ} \mathrm{C}$ at $12: 10$ pm on the center of module PV1 is observed. The edge is then $49.4^{\circ} \mathrm{C}$, that is $1^{\circ} \mathrm{C}$ less than the center. PV3 temperature is $49.5^{\circ} \mathrm{C}$ at the center and $48.0^{\circ} \mathrm{C}$ at the edge $\left(1.5^{\circ} \mathrm{C}\right.$ less). PV5 center temperature is $47.2^{\circ} \mathrm{C}$ and edge temperature is $2^{\circ} \mathrm{C}$ lower, $45.2^{\circ} \mathrm{C}$. As shown in Figure 8 (May 27 $7^{\text {th }}, 2018$ ), the temperature at the edge of the PV3 Module (PV 3b) presented around $1.5^{\circ} \mathrm{C}$ less than the center (PV 3a) from 8 am to 4:30 pm, period with highest solar irradiation.

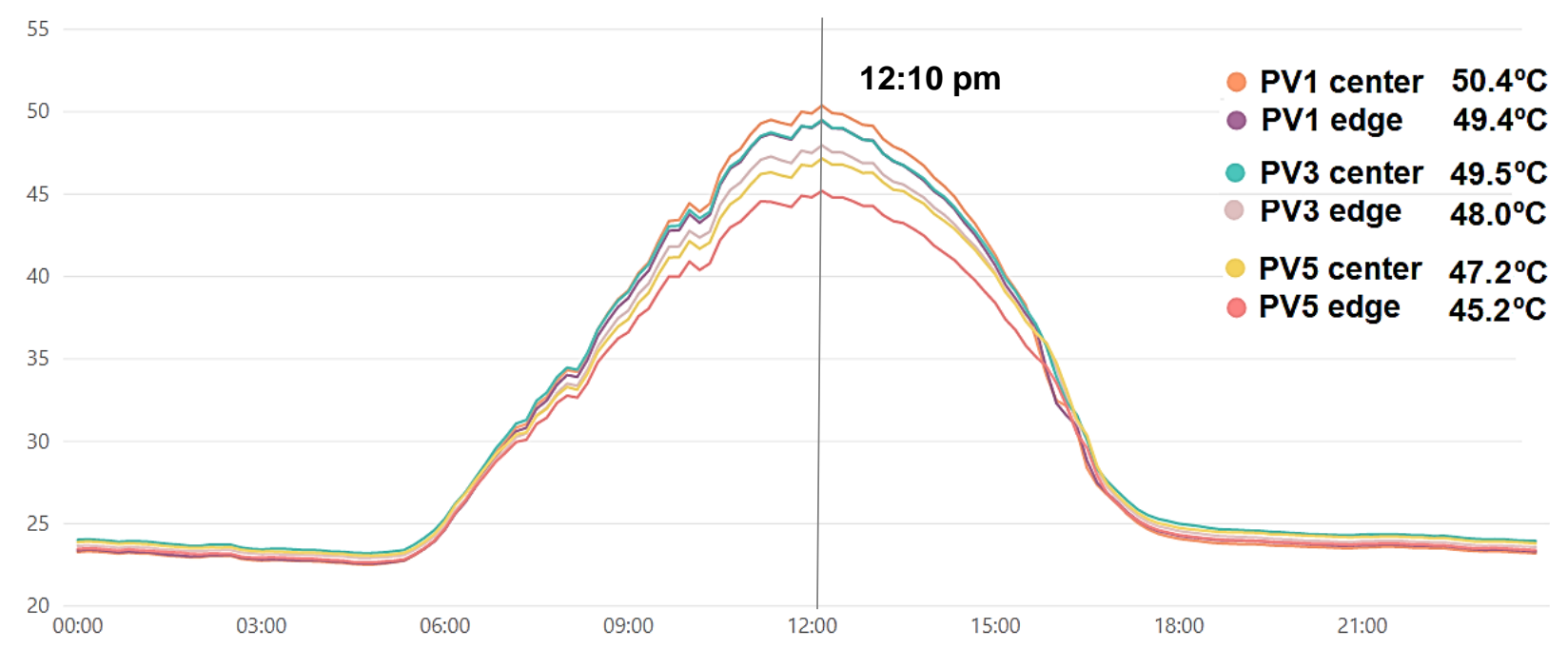

Fig. 7. Monthly average PV module temperature $\left({ }^{\circ} \mathrm{C}\right)$ in October 2018.

PV Module Temperature

05/27/2018

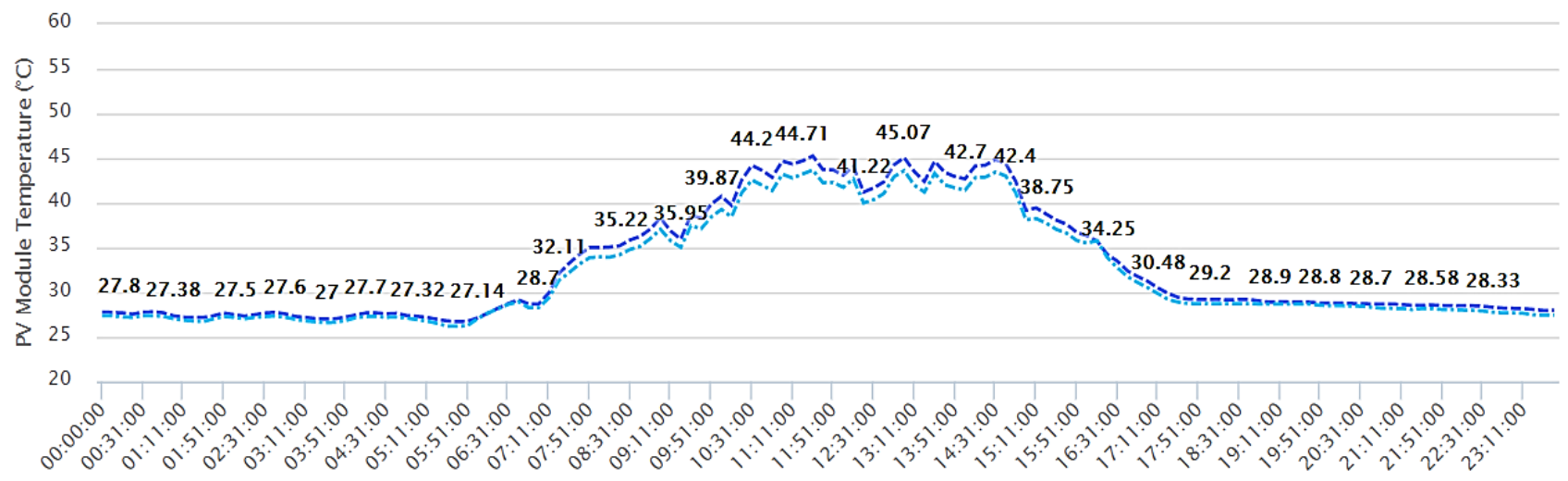

Fig. 8. PV3 module edge (PV 3b) and center (PV 3a) temperature on 05/27/2018.

According to Figure 2, the PV5 module is located to the right, in the corner of the structure, where there is higher wind circulation. The PV3 module is in the middle of the string and the PV1 module is on the left. The roof of the walkway, to the left of the string, prevents higher wind circulation to the module PV1. Figure 9 and Figure 10 compare the measured temperature of these three modules on $06 / 19 / 18$ and $06 / 21 / 18$. It is observed that at the beginning of the day, with increasing irradiance from 6:00 to 9:00 am (period indicated by arrows), the temperatures at the edge of the three modules (PV1b, 3b and 5b) are very close. As the irradiance continues to rise as from 9:00 am and the temperature increases, it is possible to observe the temperature difference between the three modules. This time required for the heat transfer is characterized by the thermal inertia of the material, which is a function of the density, specific heat and thermal capacity of the PV modules materials. The temperature difference between the modules on both days was $2.5^{\circ} \mathrm{C}$. The module on the right (PV5), with higher ventilation, reached $42.7^{\circ} \mathrm{C}$, the $\mathrm{PV} 3$ module in the center, $45.3^{\circ} \mathrm{C}$, and the PV1, on the left, showed the highest temperature, around $47.6^{\circ} \mathrm{C}$. 


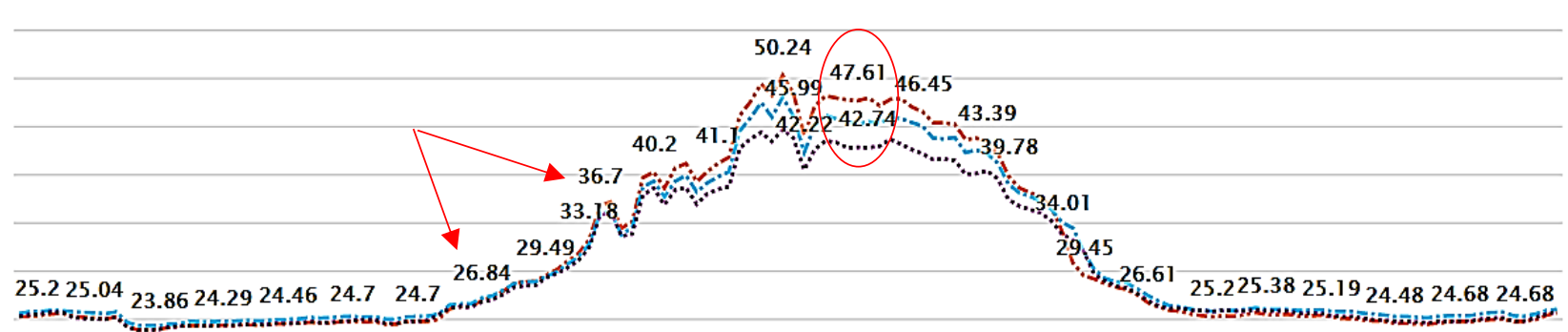

20

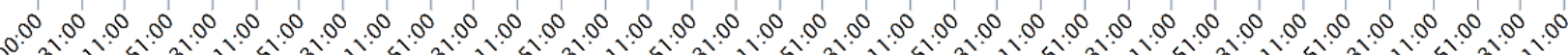

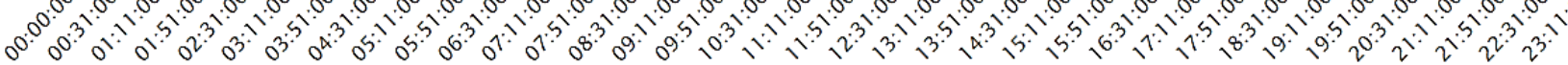

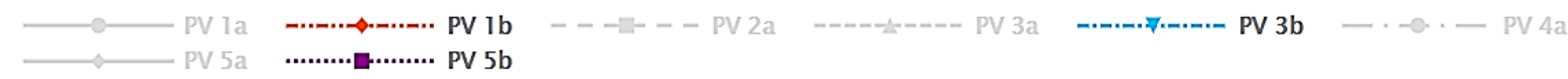

Fig. 9. PV1, PV3 and PV5 module edge temperature on 06/19/2018.

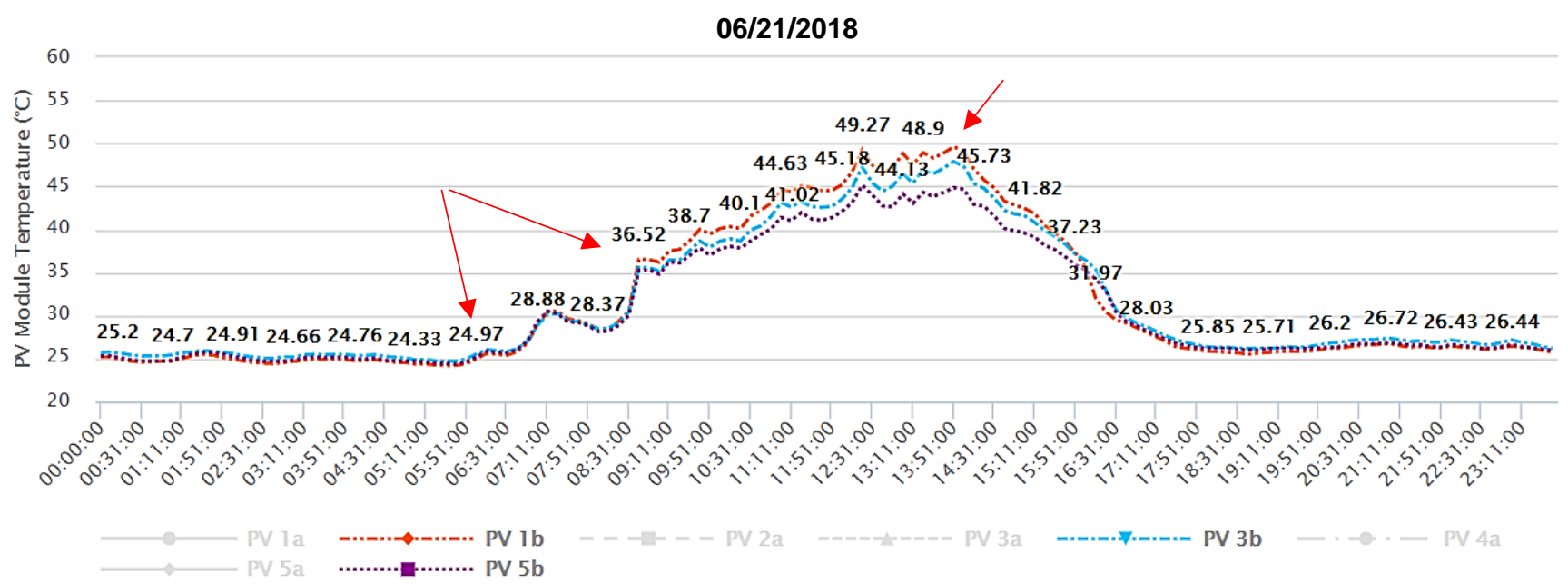

Fig. 10. PV1, PV3 and PV5 module edge temperature on 06/21/2018.

Regarding the measurements in the center of the PV module, where the temperature is higher, Figure 11 shows that the PV5 module is cooler than the others because of the position relative to the string. The temperature is $2^{\circ} \mathrm{C}$ higher on PV1 and PV3. On October $1^{\text {st }}$, 2018, Figure 12 shows that the PV5 edge (PV5b) temperature is $2^{\circ} \mathrm{C}$ lower than the center (PV5a).

$06 / 21 / 2018$

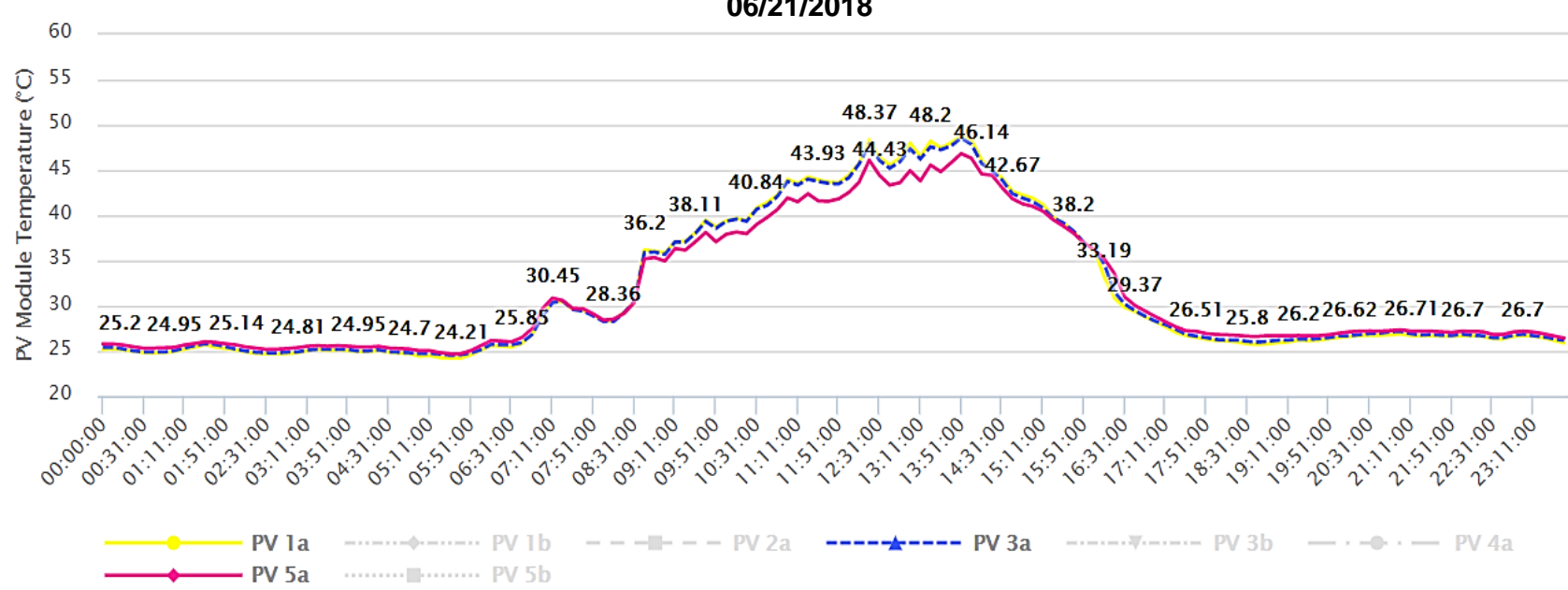

Fig. 11. PV1, PV3 and PV5 module center temperature on 06/21/2018. 
The same happens for the PV3. The difference between the center and edge temperatures is clearer when the irradiance is stable, due to thermal inertia. When the irradiance oscillates, there is no enough time for the temperature stabilization.

$10 / 01 / 2018$
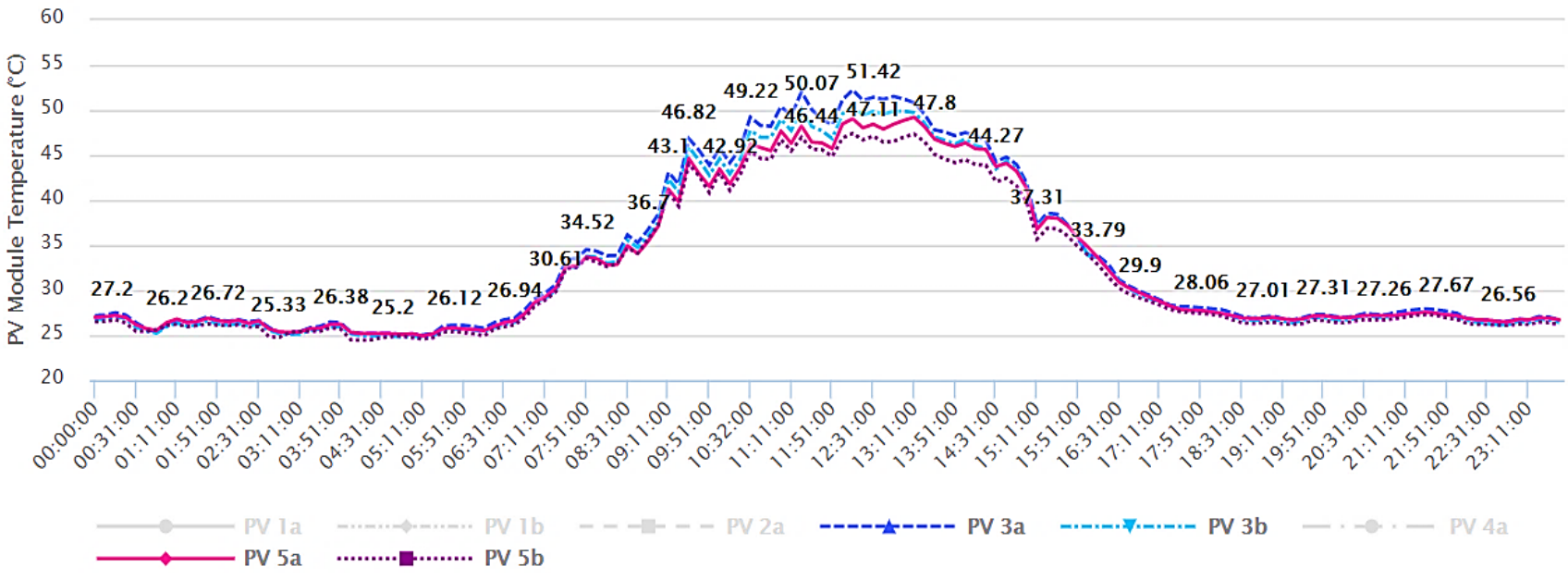

Fig. 12. PV3 and PV5 module center and edge temperature on 10/01/2018.

Figure 13 shows the temperatures at the edge of the three modules (PV1b, 3b and 5b) for December 12 $2^{\text {th }}, 2018$, particularly selected to show more clearly the difference between temperatures from 9:00 am to 4:00 pm and specifically from 10:00 am to 2:00 pm, period with higher irradiance stability (Fig. 14). The sensors can be considered calibrated since the measured temperature values at night show differences within the measurement error of $0.1{ }^{\circ} \mathrm{C}$. From 5:00 to 8:00 pm the temperature reaches $20.2^{\circ} \mathrm{C}$, due to the incidence of rainfall. Typical annual average of ambient temperature during the night in Maracanaú city is $25^{\circ} \mathrm{C}$, as can be observed in the charts presented in this paper.

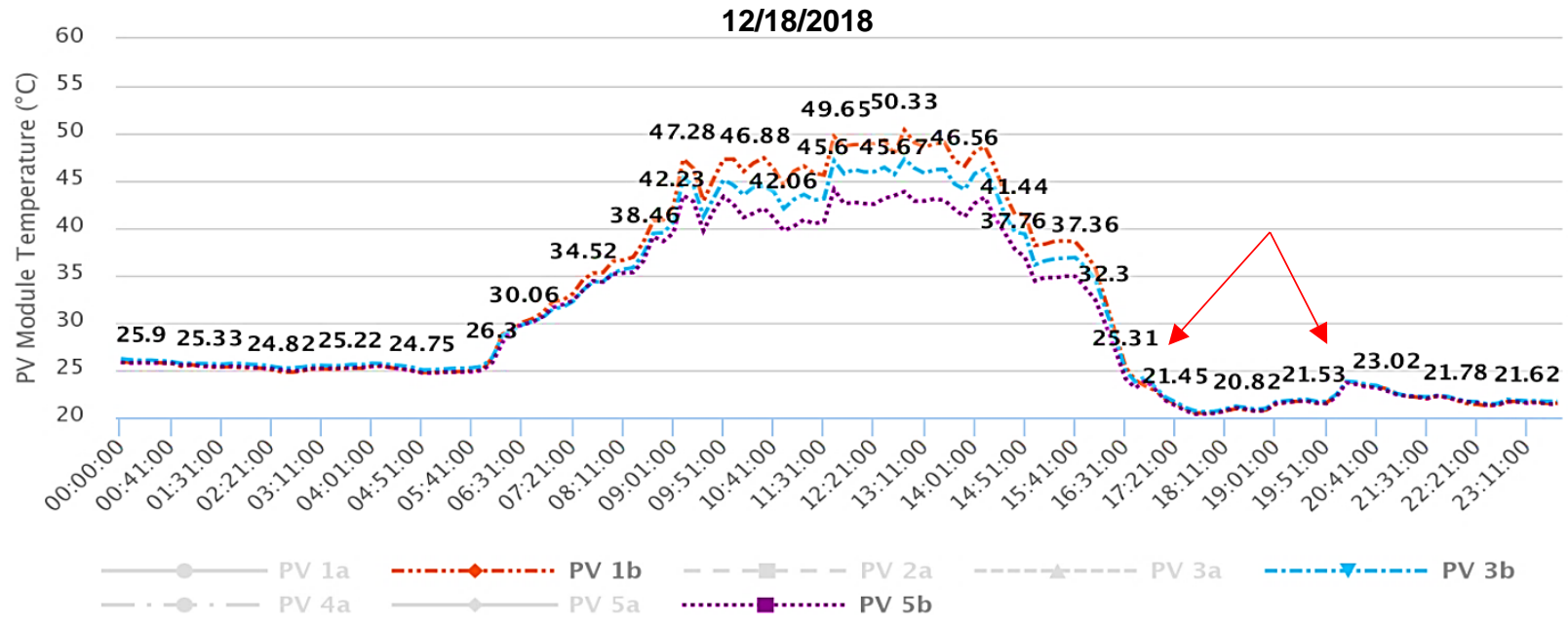

Fig. 13. PV1, PV3 and PV5 module edge temperature on 12/18/2018.

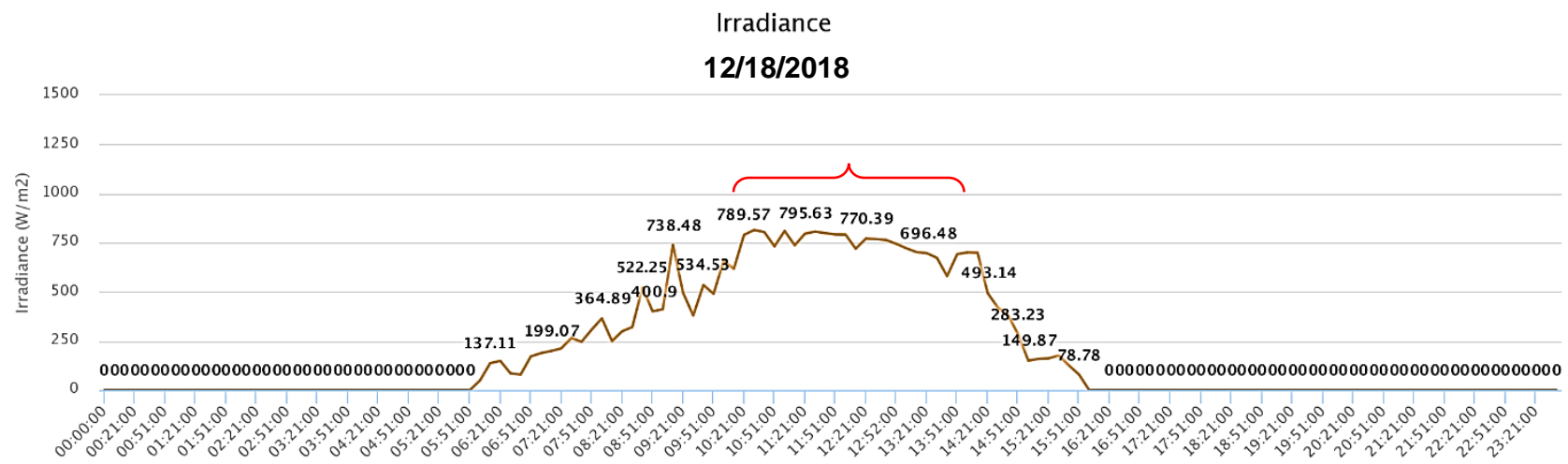

Fig. 14. Irradiance on 12/18/2018. 
Figure 15 shows the center and edge temperature of PV3 on a rainy day (February $\left.2^{\text {nd }}, 2019\right)$, as can be seen in Figure 16. We can observe that the highest peak, at 2:00 $\mathrm{pm}$ reaches $37.7^{\circ} \mathrm{C}$. This value was achieved when the irradiance was $241.7 \mathrm{~W} / \mathrm{m}^{2}$. The PV module temperature remains around the ambient temperature during the greatest part of the day when the irradiance decreases due to the rain. It can also be noted that there is no difference between center and edge temperature for low irradiance values.
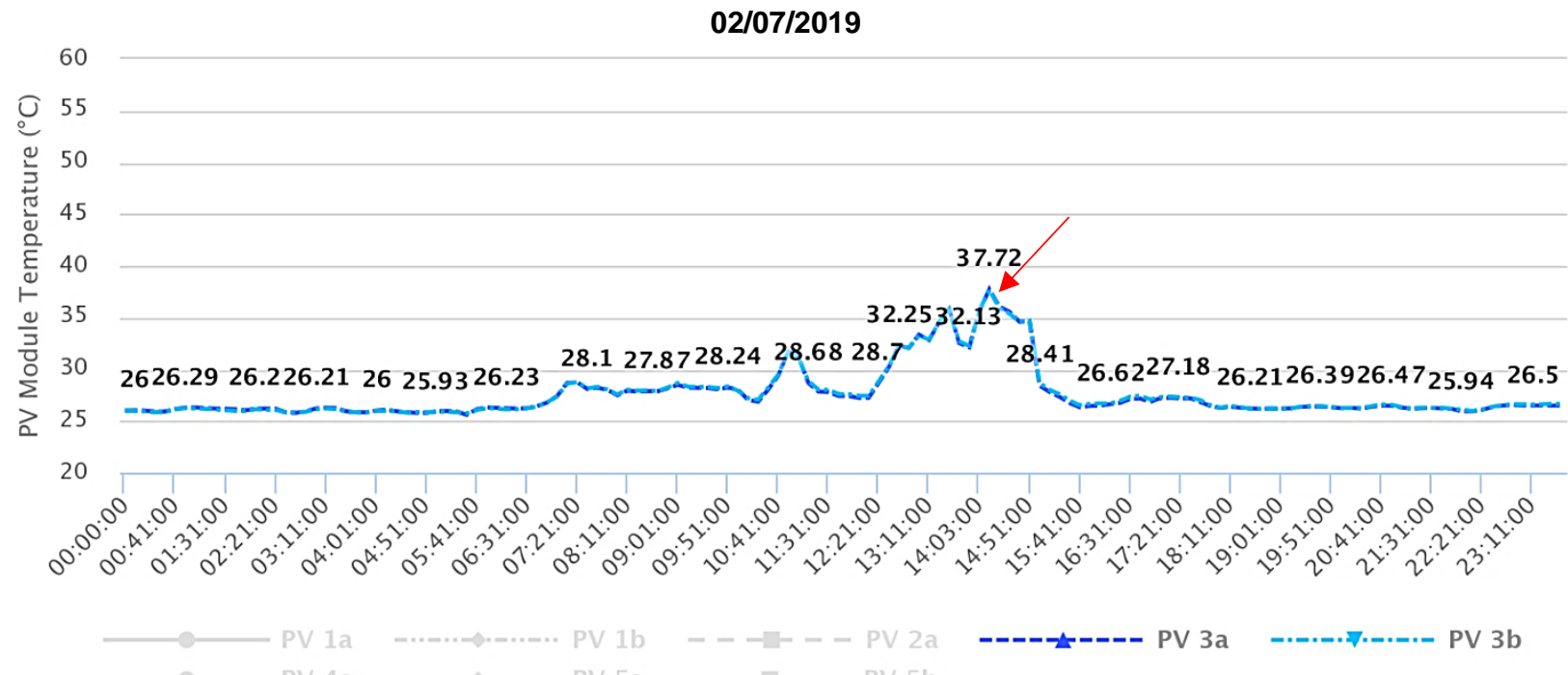

Fig. 15. PV3 module edge (PV 3b) and center (PV 3a) temperature on 02/07/2019.

Irradiance

02/07/2019

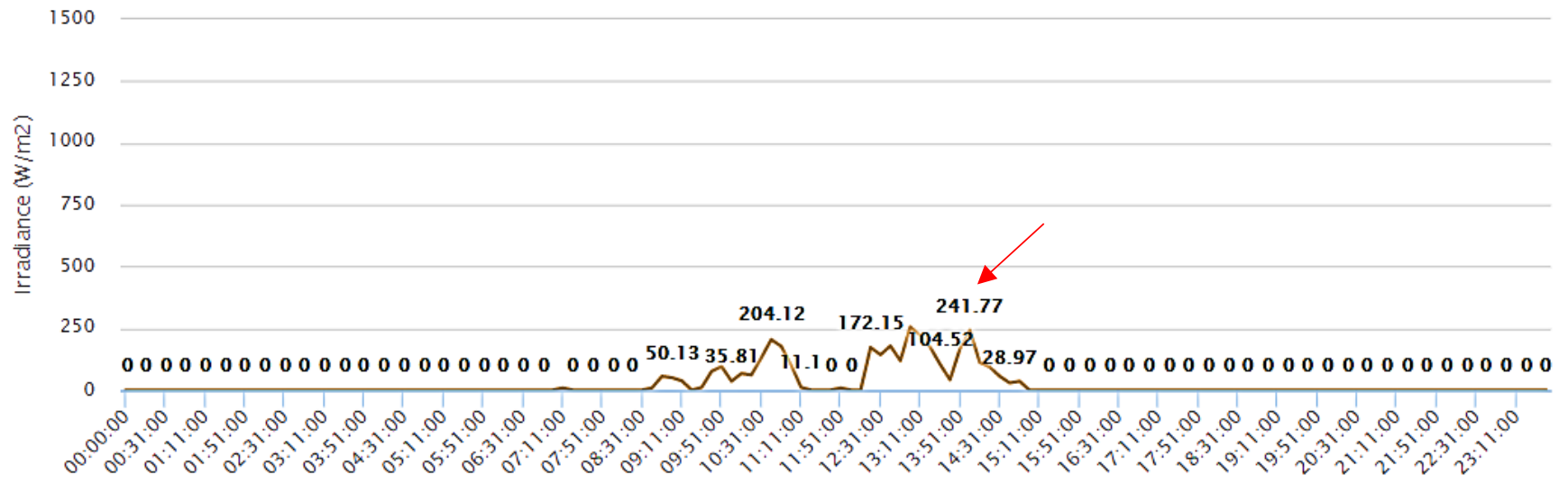

Fig. 16. Irradiance on 02/07/2019.

\section{Conclusion}

The proposed IoT monitoring is applied to monitor the temperature of individual PV modules, to provide data for the analysis of the efficiency of the electricity generation and to detect failures in case of cells overheating. The meteorological data such as solar irradiance, ambient temperature, relative humidity and wind speed were also monitored to allow a more complete analysis of the effect of these variables on the module temperature response.

Additionally, such data can provide the necessary parameters for the elaboration of mathematical models of PV modules temperature, applied for plants at regions with semiarid climate, such as the Brazilian Northeast. Thus, using the measured data it is possible to validate a mathematical model to be developed in future researches, and to compare and validate models that already exist in the literature.

From the obtained results the lowest CFs for the analyzed period were $14 \%$ in May/18 and $12 \%$ in Mar/19. The highest $(20 \%)$ ones were registered in Sep, Oct and Nov/18. Mar/19 was the month with the lowest average daily irradiance $\left(2.5 \mathrm{kWh} / \mathrm{m}^{2}\right)$ and Oct/18 the highest, 6.1 $\mathrm{kWh} / \mathrm{m}^{2}$, with monthly irradiance $189.3 \mathrm{kWh} / \mathrm{m}^{2}$. The average yearly performance ratio for the analyzed period was $91 \%$. The highest productivity was Oct/18, totaling $149.2 \mathrm{kWh} / \mathrm{kWp}$ and the lowest was $87.9 \mathrm{kWh} / \mathrm{kWp}$ registered in Mar/19. The temperature measurements showed that the PV module edge is about $1^{\circ} \mathrm{C}$ to $2^{\circ} \mathrm{C}$ lower than the center. 
For future developments, it is intended to collect more data to provide an accurate analysis of the temperature influence on electrical PV efficiency for mentioned site.

\section{Acknowledgement}

The authors would like to thank the Deutscher Akademischer Austauschdienst (DAAD) and CAPESBrazil for exchange scholarship at TH Köln-Germany and post-doctoral research scholarship (PNPD) awarded to the first author; Fundación Carolina for post-doctoral research at Uni Cádiz-Spain awarded to the second author; $\mathrm{CNPq}$ for project financial support (420133/2016-0 Universal 01/2016) and for researcher scholarship awarded to the third author; and UFC and IFCE for the availability of laboratories and equipment.

\section{References}

[1] R. I. S. Pereira, I. M. Dupont, P. C. M. Carvalho, and S. C. S. Jucá, "IoT embedded linux system based on Raspberry Pi applied to real-time cloud monitoring of a decentralized photovoltaic plant," Meas. J., vol. 114, pp. 286-297, 2018.

[2] Espressif Systems, "ESP32 Datasheet," p. 58, 2018.

[3] Espressif, "ESP8266EX Datasheet," Espr. Syst. Datasheet, pp. 1-31, 2018.

[4] L. Zhu, A. Raman, K. X. Wang, M. A. Anoma, and S. Fan, "Radiative cooling of solar cells," Optica, vol. 1, no. 1, pp. 32-38, 2014.

[5] JINKO SOLAR, “Jkm270Pp-60,” pp. 5-6, 2008.

[6] S. Dubey, J. N. Sarvaiya, and B. Seshadri, "Temperature dependent photovoltaic (PV) efficiency and its effect on PV production in the world - A review," Energy Procedia, vol. 33, pp. 311-321, 2013.

[7] T. Simioni, "O impacto da temperatura para o aproveitamento do potencial solar fotovoltaico do Brasil," 2017.

[8] E. Barykina and A. Hammer, "Modeling of photovoltaic module temperature using Faiman model: Sensitivity analysis for different climates," Sol. Energy, vol. 146, pp. 401-416, 2017.

[9] J. A. Duffie and W. A. Beckman, Solar Engineering of Thermal Processes, 4th ed. 2013.

[10] R. G. Ross, "Interface design considerations for terrestrial solar cell modules," in Proceedings of 12th IEEE photovoltaic specialists conference, 1976, pp. 801-6.

[11] R. Chenni, M. Makhlouf, T. Kerbache, and A. Bouzid, "A detailed modeling method for photovoltaic cells," Energy, pp. 1724-30, 2007.

[12] B. D. O. Busson, P. Hassan, M. Campos, P. Cesar, and M. De Carvalho, "Validação de modelos de comportamento térmico de painéis fotovoltaicos para o semiárido brasileiro," 2018.

[13] K. Ashton, "That 'Internet of Things' Thing," RFiD J., p. 4986, 2009.

[14] J. Liu, Y. Li, M. Chen, W. Dong, and D. Jin, "Softwaredefined internet of things for smart urban sensing," IEEE Communications Magazine, vol. 53, no. 9, pp. 5563, 2015.

[15] S. Andreev et al., "Understanding the IoT connectivity landscape: a contemporary M2M radio technology roadmap," IEEE Commun. Mag., vol. 69, no. 7, pp. 3240, 2015

[16] H. D. Mohammadian, "Internet of Energy: a solution for improving the efficiency of reversible energy," in IEEE
Global Engineering Education Conference (EDUCON), 2018, pp. 1890-1895.

[17] C. Rong, S. T. Nguyen, and M. G. Jaatun, "Beyond lightning: A survey on security challenges in cloud computing," Comput. Electr. Eng., vol. 39, no. 1, pp. 47-54, 2013.

[18] H. E. Gad and H. E. Gad, "Development of a new temperature data acquisition system for solar energy applications," Renew. Energy, vol. 74, pp. 337-343, 2015.

[19] F. J. Ferrero Martín, M. Valledor Llopis, J. C. Campo Rodríguez, J. R. Blanco González, and J. Menéndez Blanco, "Low-cost open-source multifunction data acquisition system for accurate measurements," Meas. J. Int. Meas. Confed., vol. 55, pp. 265-271, 2014.

[20] N. Instruments, "LabVIEW," 1986. [Online]. Available: http://www.ni.com/labview/. [Accessed: 24Jan-2017].

[21] N. Erraissi, M. Raoufi, N. Aarich, M. Akhsassi, and A. Bennouna, "Implementation of a low-cost data acquisition system for 'PROPRE.MA' project," Meas. J. Int. Meas. Confed., vol. 117, no. December 2017, pp. 21-40, 2018.

[22] D. Pasalic, D. Bundalo, Z. Bundalo, and B. Cvijic, "ZigBee-based data transmission and monitoring wireless smart sensor network integrated with the Internet," 2015 4th Mediterr. Conf. Embed. Comput., pp. 240-243, 2015.

[23] R. I. S. Pereira, S. C. S. Jucá, and P. C. M. Carvalho, "IoT embedded systems network and sensors signal conditioning applied to decentralized photovoltaic plants," Measurement, vol. 142, pp. 195-212, 2019.

[24] British Standard, "IEC 61724: 1998. Photovoltaic system performance monitoring - Guidelines for measurement, data exchange and analysis." 1998.

[25] R. I. S. Pereira, S. C. S. Jucá, and P. C. M. de Carvalho, "Online Monitoring System for Electrical Microgeneration via Embedded WiFi Modem," IEEE Lat. Am. Trans., vol. 14, no. 7, pp. 3124-3129, 2016.

[26] R. I. S. Pereira, P. C. M. Carvalho, and S. C. S. Jucá, "WiFi Data Acquisition System and online monitoring applied to thermoelectric microgeneration modules," Renew. Energy Power Qual. J., no. 13, pp. 1-6, 2015.

[27] PHB, "INVERSOR SOLAR FOTOVOLTAICO PHB 1500-NS." 2017.

[28] IEA, "Technology Roadmap, Solar Photovoltaic Energy," Paris, 2014.

[29] A. D. S. Rabelo, D. A. C. Costa, P. C. M. de Carvalho, and Virgílio Peixoto Távora, "Estudo Sobre Sujidade Em Planta Fotovoltaica Localizada Em Zona Urbana," in Congresso Brasileiro de Geração Distribuída, 2017, pp. 1-7. 